\title{
SURFACE TO CAVE DYE TRACING: LESSONS LEARNED FROM THE BELGIAN KARST
}

\author{
Amaël Poulain \\ Department of Geology - University of Namur, Rue de Bruxelles nº1, Namur, B-5000, Belgium, \\ amael.poulain@unamur.be
}

Arnaud Watlet

Royal Observatory of Belgium, Avenue Circulaire n³, Bruxelles, B-1180,Belgium, arnaud.watlet@umons.ac.be

\section{Gaëtan Rochez}

Department of Geology - University of Namur, Rue de Bruxelles nº1, Namur, B-5000, Belgium, gaetan.rochez@unamur.be

\section{Olivier Kaufmann}

Department of Geology and Applied Geology - University of Mons, Rue de Houdain n9, Mons, B-7000, Belgium, olivier.kaufmann@umons.ac.be

\section{Michel Van Camp}

Royal Observatory of Belgium, Avenue Circulaire n³, Bruxelles, B-1180,Belgium,mvc@oma.be

\section{Romain Deleu}

Department of Geology - University of Namur, Rue de Bruxelles n61, Namur, B-5000,Belgium, romde3@live.be

\section{Yves Quinif}

Rue des Ecaussinnes n87, Le Roeulx, B-7078,Belgium, yves.quinif2@gmail.com

\section{Vincent Hallet}

Department of Geology - University of Namur, Rue de Bruxelles nº1, Namur, B-5000, Belgium, vincent.hallet@unamur.be

\begin{abstract}
The vadose zone (unsaturated) of karst aquifers is critical for several reasons. (1) It is the main pathway for karst groundwater recharge from the surface to the phreatic zone (saturated), (2) it forms the transition zone between surface human activities (potential contamination) and the groundwater resource, and (3) it gives a support for karst fauna and flora through its hydrogeological dynamic. The hydrogeological functions of the vadose zone are of growing interest for these reasons but, also, because this highly heterogeneous media is still poorly understood by hydrogeologists and karst researchers.
\end{abstract}

In order to more fully apprehend the function of this zone, surface to cave dye tracing was performed above the Rochefort Cave in south Belgium. The goal was to explore the hydrological processes of the 30 -meters vadose zone between the surface and the cave by mean of dyes and drip-water monitoring. These methods enable us to discover information about groundwater dynamic. A maximum velocity of around 10 meters/ hour was calculated in absence of rainfall and without significant flush during the injection of the dye. A multimodal breakthrough curve was recorded in the percolation water, the tracer being remobilized by every rainfall event during more than 120 days. The dye tracked the reaction of the percolation to rainfall events at the surface. Separation and analysis of the different peaks and their related rainfall events revealed a clear trend. The higher the rainfall intensity, the faster the reaction of the percolation. The effect of the rainfall gives infiltration velocities from 10 to $55 \mathrm{~m} / \mathrm{h}$ for the higher rainfall intensities. Additionally, the dye tracing allowed us to compare the effect of snowmelt and 
rainfall on the infiltration efficiency. Snowmelt has a higher remobilization effect on the dye, thus a higher infiltration potential compared to rainfall events. The effect of rainfall intensity on infiltration velocity and the difference between snowmelt and rainfall when considering infiltration efficiency seems of primary importance in a context of global climate changes. These results emphasize the importance of evaluating vadose processes in karst terrain.

\section{Introduction}

The karstic vadose zone is a highly heterogeneous media located between the ground surface and the phreatic zone of karst aquifers. The hydrogeological functions of this zone are difficult to assess given its spatial heterogeneity and the variety of processes occurring in its different parts: soil, epikarst and transmission zone (Bakalowicz, 1995; Williams, 2008). The pathway and effects of precipitation (rainfall and snowmelt) on recharge of the karst aquifer through the vadose zone is uncertain. For example, the following is not understood: water transit, pressure transfers, temporary storage, horizontal dispersion, mixing between recently infiltrated water and "old" water. Many of these processes may occur in this part of the aquifer.

While the vadose zone is an important part of the karst aquifer given its location, it remains poorly studied by karst scientists. It is important to study and understand the karst vadose zone for many reasons. For example, the vadose zone collects and drives autogenic recharge from the surface to the water table. This recharge is crucial for karst aquifers that are extensively exploited for human activities around the world. What are the processes and factors influencing this recharge inside the vadose zone? Are they subject to changes? Also, due to its position between the surface and the groundwater resource, the vadose zone is often the only protective layer between surface activities and potential contamination. Knowledge of vadose hydrogeological processes will assist in evaluating the vulnerability of groundwater and implement sustainable protection programs. In addition, the vadose zone is the main support for the fauna and flora of karst ecosystems. Vegetation will be able to grow and subterranean life is dependent of vadose water to live.

The hydrogeological dynamic of the karst vadose zone can be explored by in-cave experimentations and monitoring. In particular, cave percolations (stalactite, fissures) may be studied to measure this dynamic. In this study, a cave percolation under a 30-meter thick vadose zone was used to perform a surface to cave dye trace with fluorescein and a compact field fluorometer. The aim was to highlight the infiltration behavior, groundwater velocity and residence time in vadose zone. In addition, the percolation was monitored for discharge, temperature, and electrical conductivity.

\section{Study Site}

The percolation monitoring and dye trace were conducted in the vadose zone of the Rochefort Cave, being one of the main karst network in Belgium (Figure 1). The cave is located in Givetian limestones, which are highly

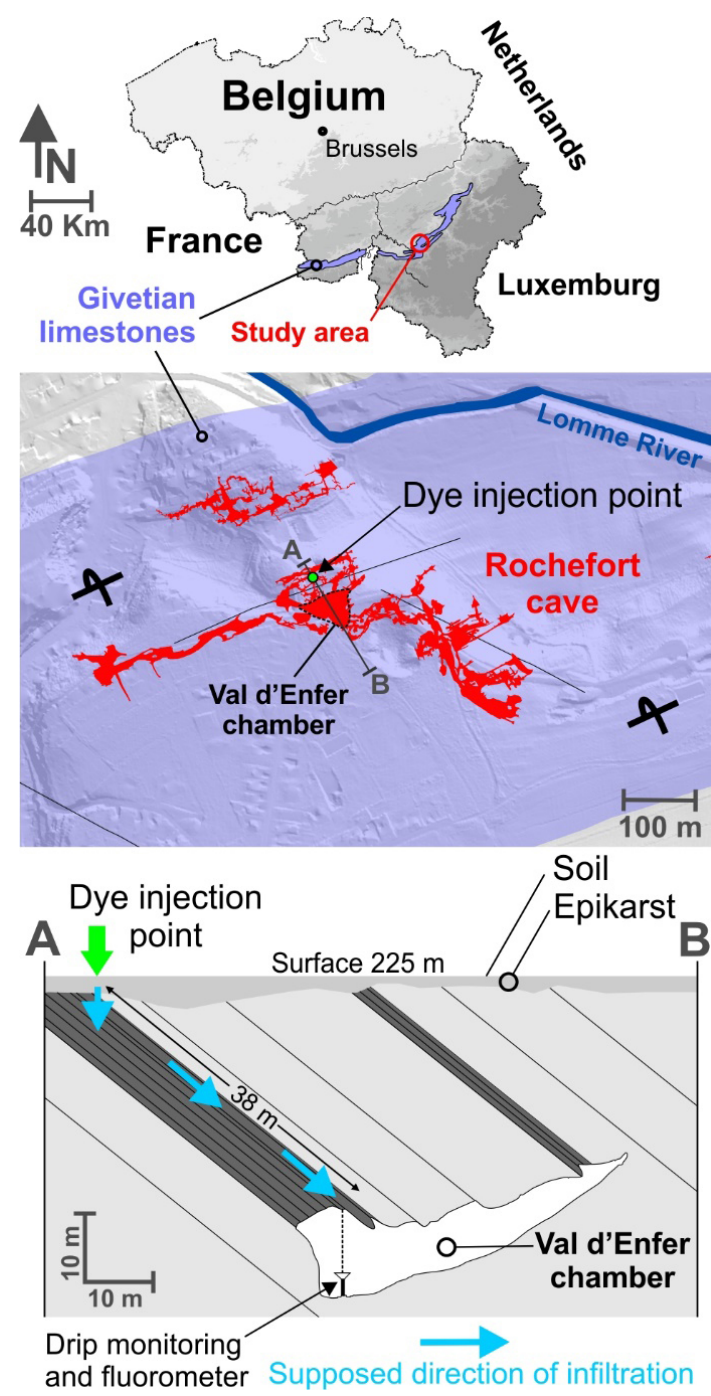

Figure 1. Location of the study site in south Belgium with the dye injection point at the surface and monitoring station in the Rochefort Cave. 
fractured with a $45^{\circ}$ south dipping strata. The vadose zone at this location is composed by a 30 -meter thick layer of biostomal limestones with clayed beds. The percolation is located in the Val d'Enfer chamber. It is a perennial percolation from a fracture in clayey limestone.

\section{Methodology}

The dye trace was performed in March 2016. 500 grams of fluorescein was used. The dye was diluted with 40 liters of water and injected directly on the ground with a PVC-pipe in order to simulate a single point injection (Figure 2). The soil was not removed and the dye was injected with a limited flush in order to approximate natural conditions of infiltration (Kogovsek, 2010; Poulain et al., 2015). Rainfall, snow levels and air temperature were sampled above the cave $(1$ minute sampling). A Campbell T10 with a $0.03^{\circ} \mathrm{C}$ resolution and $0.03^{\circ} \mathrm{C}$ precision was used for the air temperature, while rainfall and snow were measured with a Lufft rain gauge with a $0.1 \mathrm{~mm}$ resolution. Inside the cave, the drip discharge was made with an auto-siphoning gauge (Kaufmann et al., 2016) which can accommodate a high range of discharge. Fluorescein monitoring was performed every 5 minutes with a Fluo-Green compact fluorometer (Poulain, 2017; Poulain et al., 2017) that was installed above the drip gauge (Figure 2). Additional measurement of temperature and electrical conductivity were made on the drip water. The measurement was made in a small bath ( 5 liters) so the buffer effect was considered negligible due to the high percolation discharge.

\section{Results}

Figure 3 shows the results of the vadose dye tracing and monitoring for 3 months between March and June 2016, as recorded in the percolation water. The first appearance of the fluorescein was $3 \mathrm{~h} 45$ after the injection for a minimal straight line distance of 38 meters. The maximum infiltration velocity is 10.25 meter/hour. The breakthrough curve exhibits a multimodal behavior with a restitution time longer than 120 days.

The fluorescein concentration shows a slow increase during the first 15 hours of restitution and then a sharp peak up to $225 \mathrm{ppb}$. This peak is associated with a rainfall event at the surface and a discharge increase. The duration of this increase is short (15 to 20 hours) but such rainfall-associated peaks are visible 16 times on the breakthrough curve. The maximum dye concentration of the peaks decreases as the restitution goes on, indicating a defined amount of dye that is slowly remobilized. The dye recovery was calculated based on the drip

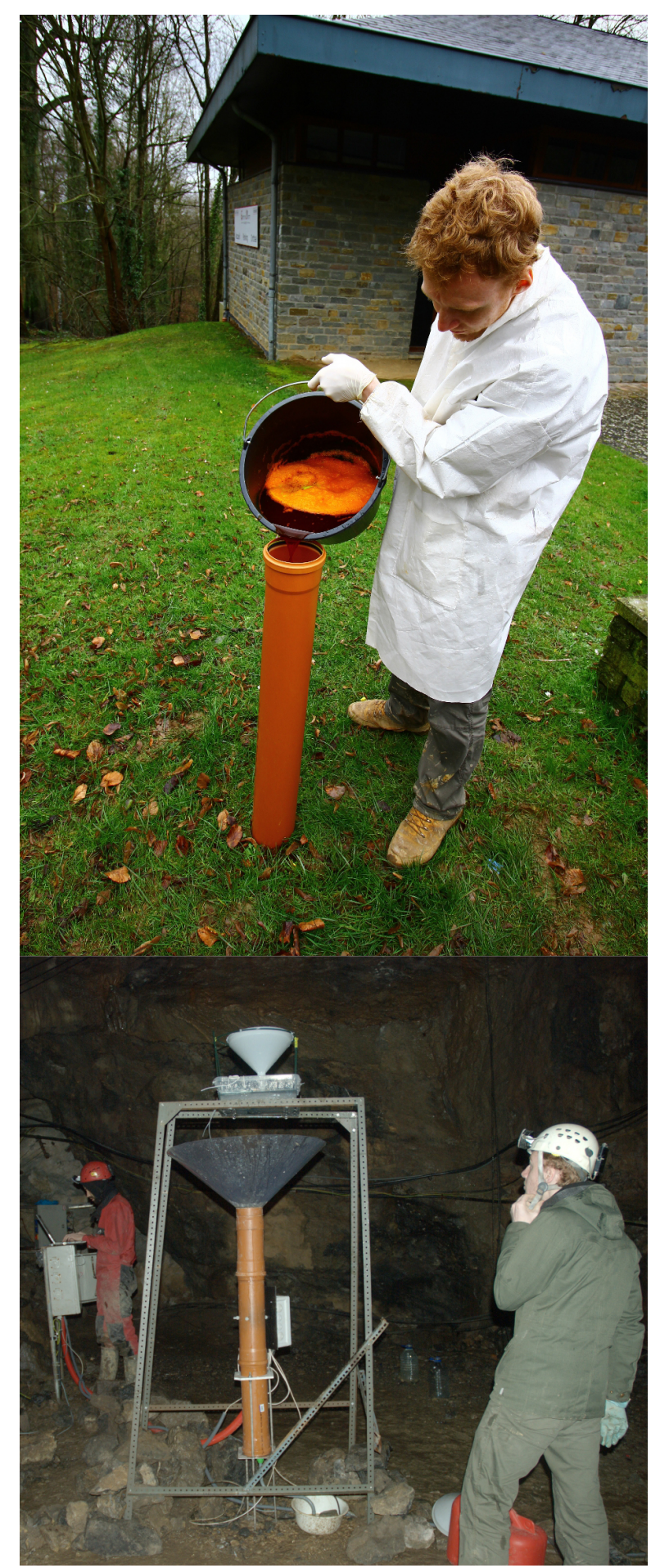

Figure 2. Injection of fluorescein above the cave with a PVC-pipe and a 40-liters flush of water. The monitoring is made of a Fluo-Green fluorometer above a drip water gauge. 


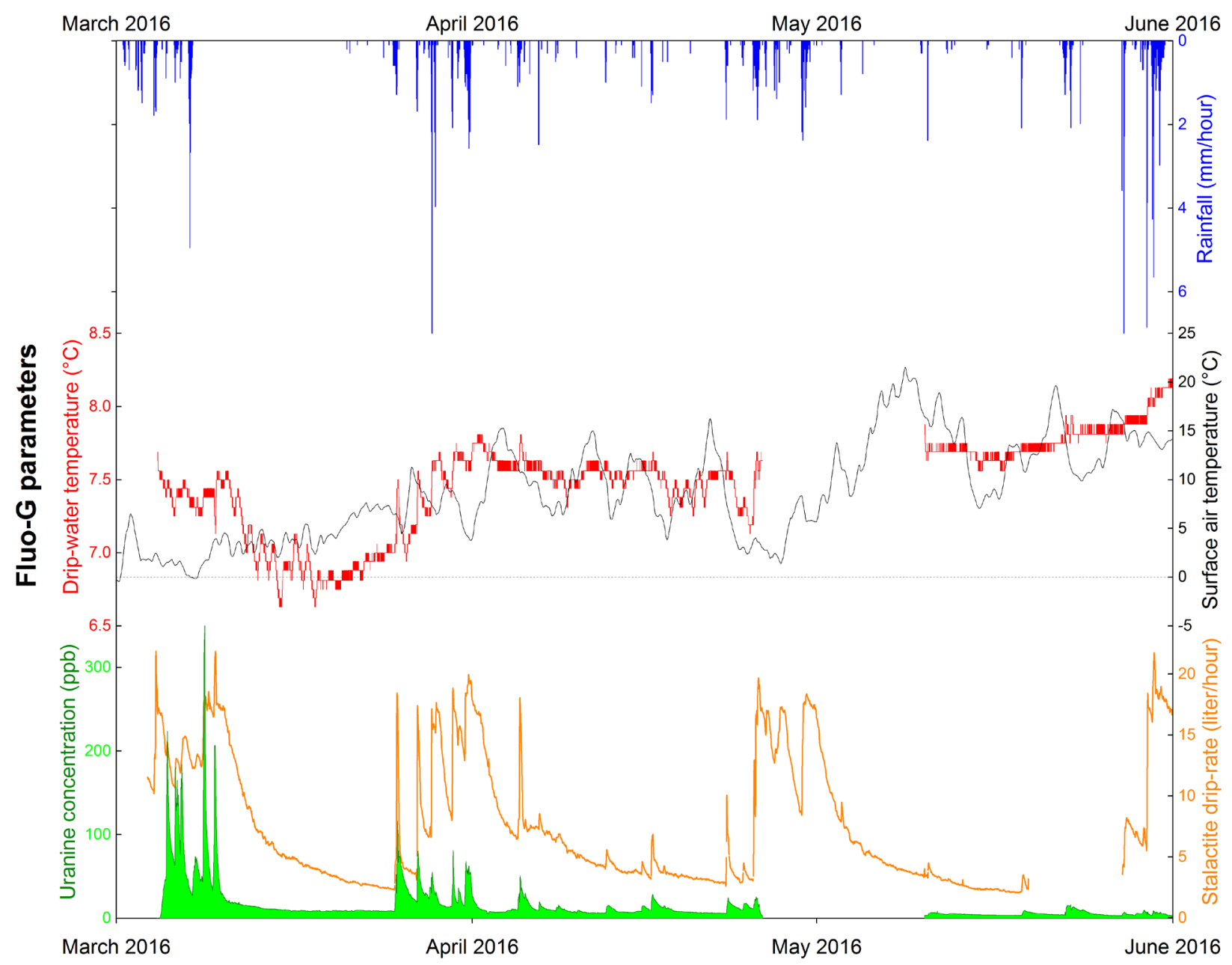

Figure 3. Surface and percolation monitoring results during the surface to cave dye trace.

discharge that range from 4 to 20 liters/hour. $0.345 \mathrm{~g}$ of fluorescein was recovered, giving a restitution rate of $0.07 \%$.

The secondary breakthrough curve triggered by rainfall events further demonstrates the infiltration dynamic through the vadose zone. When normalized on a 0 to 1 scale for concentration, the breakthrough curves exhibit similar characteristics in terms of first arrival, peak time and total restitution time (Figure 4). It is possible to calculate the average behavior showing the characteristics of infiltration transit in this vadose zone during a rainfall event. Mean first arrival is $1 \mathrm{~h} 30$ (maximum velocity of 25.7 meter/hour), mean peak time is $4.2 \mathrm{~h}$ (modal velocity of $9 \mathrm{~m} / \mathrm{h}$ ). Nevertheless, it was not possible to control the migration of the dye and any change in the remobilization travel distance that might influence the velocity. Although this effect might exist, it was considered non-significant since the calculated velocities did not increase with time for similar rainfalls conditions.

Plotting the reaction time of the percolation versus the rainfall event (appearance of the secondary restitution peak) against the rainfall intensity shows a negative dependency (Figure 5). Higher rainfall intensities result in faster reactions of the percolation and higher infiltration velocities up to $55 \mathrm{~m} / \mathrm{h}$.

Finally, two secondary peaks of the breakthrough curve where triggered by snow cover melting (Figure 6). While it is risky to draw conclusions based on only two occurrences, one may clearly see that the concentration of those peaks is higher than those triggered by rainfall. This may indicate that snowmelt has a different behavior than rainfall when infiltrating through vadose zone. 


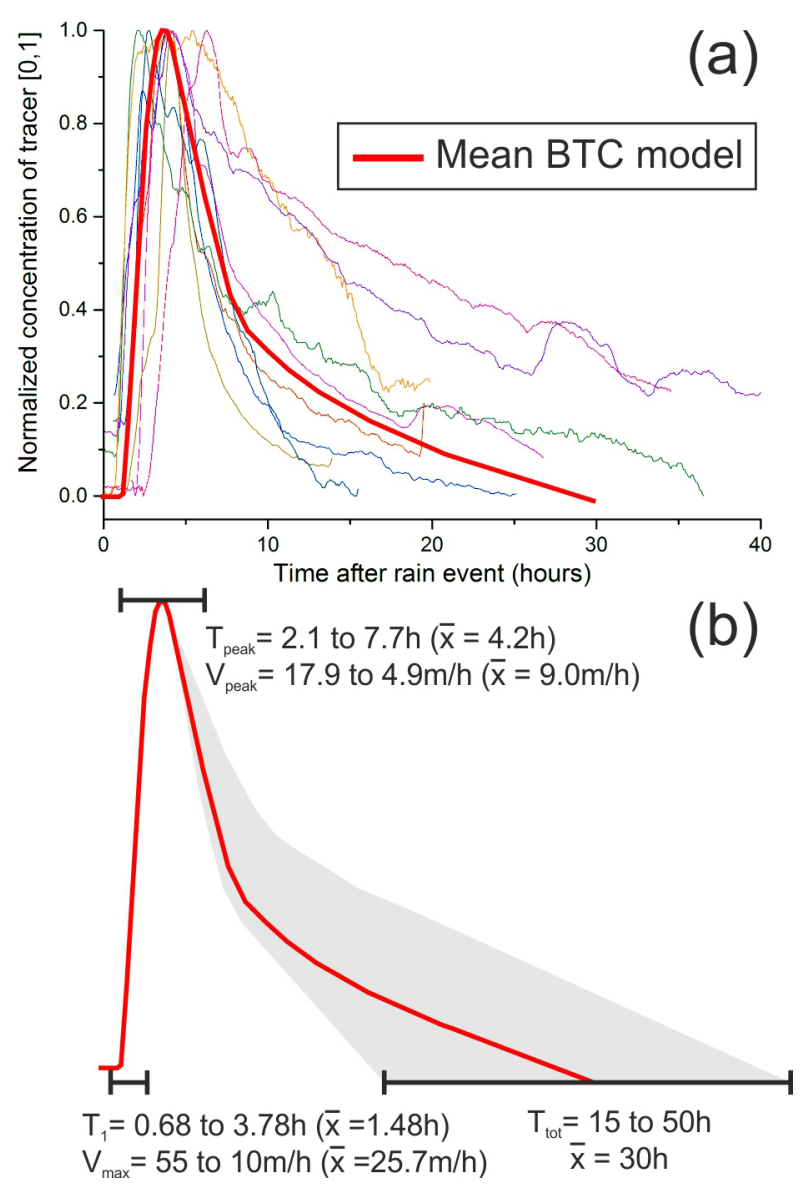

Figure 4. (a) Individual breakthrough curves for the 16 rainfall-associated peaks of dye, (b) mean behavior of the infiltration due to rainfall.

\section{Discussion}

The dye trace conducted in the vadose zone of the Rochefort Cave gives us quantitative information about hydrological dynamic in this part of the aquifer.

Diffuse infiltration through the karst vadose zone is a very quick process. Even without clear infiltration points such as a sinkhole or swallet, the process is efficient and shows velocities ranging from 10 to $55 \mathrm{~meter} /$ hour. If surface contamination were present, groundwater would quickly be threatened and the contaminant may spread over large distances. In terms of such vulnerability, the karst vadose zone is not an effective protection media. It is a place where quick and concentrated flow take place, with limited attenuation.

Even with this quick flow component, the heterogeneity of the vadose zone and the diversity of the hydrologic processes there result in prolonged storage of

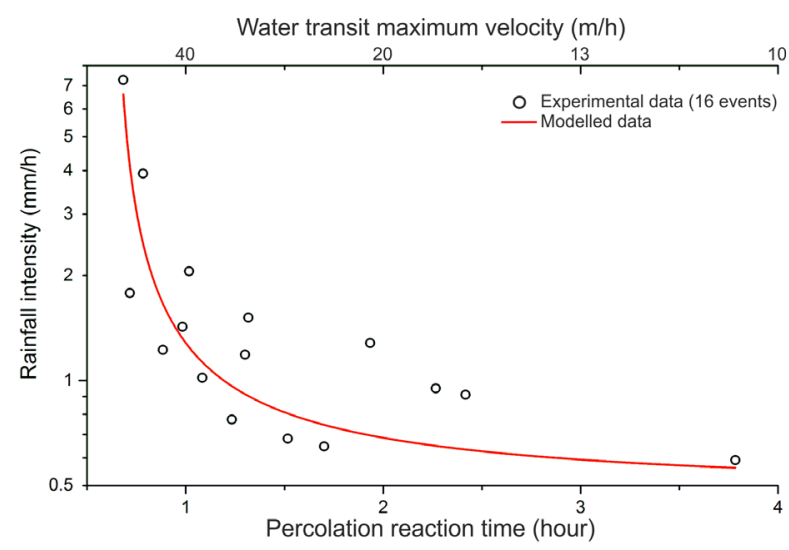

Figure 5. Relationship between rainfall intensity and the reaction time of the percolation to the rainfall event. The top $X$-axis gives the maximum transit velocity in the vadose zone.

groundwater. The infiltration spreads horizontally and may be temporary stored during several months. For this reason, contamination may have long term consequences. The restitution rate of this experiment clearly shows the large spreading and dilution of infiltration which might be catastrophic in case of contamination.

The dye trace highlights the importance of two factors in the vadose infiltration process. First, the intensity of the rainfall event affects the effectiveness of the infiltration. More intense rainfalls trigger faster infiltration processes and thus a more efficient recharge. In this case, the infiltration velocity is up to 5 times higher for the most intense rainfalls. Secondly, the type of precipitation input (snowmelt of rainfall) may have an effect on the infiltration efficiency but requires further data to be quantified precisely.

\section{Conclusion}

In a context of climate changes and global modifications of the water cycle, it is important to understand the

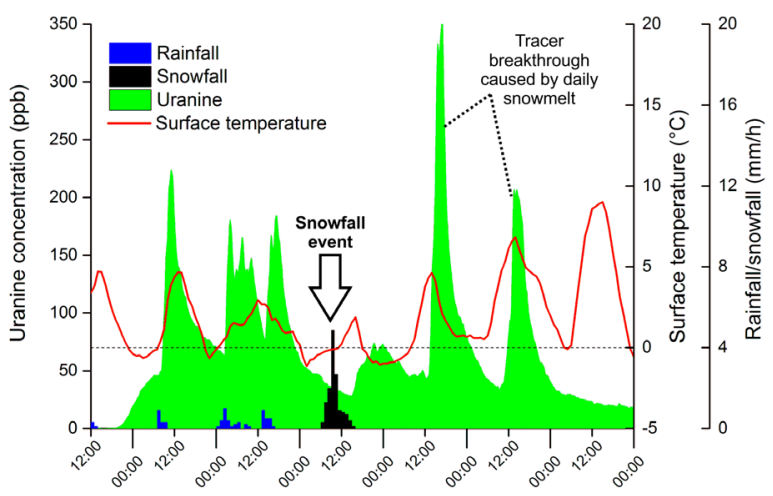

Figure 6. Secondary restitution peaks caused by snow melting. 
reaction of karst aquifer to extreme weather events, as is reported in many recent studies (Murakami et al., 2017; Thompson et al., 2017; Wang et al,. 2017), together with modifications of atmospheric temperature and thus precipitation type. Our field results indicate that these factors may be determinant for the recharge process of karst aquifers. Thus, it is expected that both quality and quantity of karst groundwater resource will be affected by those changes. In addition, the growing pressure of surface anthropogenic activities is a threat for the groundwater resource and future water supply. Our results emphasize the need for adapted protection solutions to limit the impacts of potential contaminants on the groundwater, especially in karst regions. Further experimentation and monitoring in the vadose zone seems necessary to tackle this specific issue by providing reliable field data.

\section{References}

Bakalowicz M. 1995. The infiltration zone of karst aquifers. Investigation methods, structure and behavior. Hydrogéologie 4: 3-21.

Kaufmann O, Bastin C, Barcella C, Watlet A, Van Ruymbeke M. 2016. Design and calibration of a system for monitoring highly variable dripwater flows in caves. Proceedings of the 5 th International Geologica Belgica Meeting; Mons, Belgium (26-29 January).

Kogovsek J. 2010. Characteristics of percolation through karst vadose zone. Postojna - Ljubjana (Slovenia): ZRC Publishing.

Murakami H, Vacchi GA, Underwood S. 2017. Increasing frequency of extremely severe cyclonic storms over the Arabian Sea. Nature Climate Change. https://doi.org/10.1038/s41558-0170008-6.

Poulain A. 2017. Flow and transport characterization in vadose and phreatic zones of karst aquifers. $\mathrm{PhD}$ Thesis, University of Namur, Belgium, 226p.

Poulain A, Rochez G, Van Roy JP, Dewaide L, Hallet V, De Sadelaer G. 2017. A compact field fluorometer and its application to dye tracing in karst environments. Hydrogeology Journal 25: 1517-1524.

Poulain A, Rochez G, Bonniver I, Hallet V. 2015. Stalactite drip-water monitoring and tracer tests approach to assess hydrogeologic behavior or karst vadose zone: case study of Han-sur-Lesse. Environmental Earth Science 74: 7685-7697.

Thompson V, Dunstone NJ, Scaife AA, Smith DM, Slingo JM, Brown S, Belcher SE. 2017. Nature Communications 8: 107.
Williams P. 2008. The role of epikarst in karst and cave hydrogeology: a review. International Journal of Speleology 37: 1-10.

Wang G, Wang D, Trenberth KE, Erfanian A, Yu M, Bosilovich MG, Parr DT. 2017. The peak structure and future changes of the relationships between extreme precipitation and temperature. Nature Climate Change Y: 268-274. 